\title{
Transformation of Higher Education into New Normal
}

\author{
Osman Ferda Beytekin ${ }^{1}$ \\ ${ }^{1}$ Faculty of Education, Ege University, Izmir, Turkey \\ Correspondence: Osman Ferda Beytekin, Faculty of Education, Ege University, Izmir, Turkey. E-mail: \\ ferda.beytekin@ege.edu.tr
}

Received: July 11, $2021 \quad$ Accepted: August 9, $2021 \quad$ Online Published: August 15, 2021

doi:10.5539/hes.v11n3p125

URL: https://doi.org/10.5539/hes.v11n3p125

\begin{abstract}
The purpose of this qualitative study was to get a better understanding of faculty members' views on the future of higher education by their first-time online teaching experiences during the Fall 2021 academic semester, which was impacted by the COVID-19 pandemic. Due to the outbreak's rapid and widespread dissemination, it created a unique phenomenon that had a significant impact on faculty members who had no prior experience teaching courses entirely online. In order to conduct this qualitative research, purposive sampling was used to choose ten faculty members from a variety of disciplines who had at least ten years of experience teaching in a traditional classroom setting at a public university in Izmir, Turkey. Faculty members were asked about the future of higher education in the aftermath of the COVID-19 pandemic. Apart from that, each faculty member was asked to discuss how the mandatory shift to online education altered their teaching style and how institutional help impacted their experiences throughout the pandemic. As a consequence of their observations and statements of their perspectives on events they witnessed and personally experienced, the key issue of "transformation of higher education with hybrid perspective" developed as a central theme. The data analysis revealed the following subthemes: "educators on the internet," "sustain and evolve," and "university support". These findings may be applied in a variety of contexts, including educational leadership and the design of hybrid and online courses, among other applications in higher education.
\end{abstract}

Keywords: higher education, transformation, hybrid perspective, online education, pandemic

\section{Introduction}

Universities use online courses and programs to extend the higher education learning experience to students who reside outside the physical limits of their institutions' campuses. Aside from that, the flexibility and ease of online learning have made the goal of obtaining an advanced degree a reality for individuals who have substantial work and personal obligations on their shoulders. The process of digital transformation in higher education has already been going on for a long time, but the increase in the frequency of these events has caused even more significant shifts in a matter of weeks. Many higher education institutions realize that instructional techniques, critical competencies and evaluation systems are being revolutionized by technology (Jensen, 2019; Arslan \& Ulutaş, 2017). When faced with these constraints, students find that the conventional on-campus educational experience is not a reasonable strategy. Johnson et al. (2016) showed that while instructors utilize digital technology in their own lives, they somehow face major technical, logistical and pedagogical challenges when it is used in classrooms. The vast majority of higher education administrators, faculty members and staff acknowledge that online programs are the primary route to graduation for these students; but online education is also becoming an increasingly feasible alternative for students who are able to attend on-campus sessions as well. Technological developments keep improving the design and implementation of online courses and programs, thus ensuring the higher professional development of faculty and making online education a more attractive mode of teaching for students with special educational needs. The COVID-19 outbreak has compelled many universities to immediately switch to the online delivery of lessons. Many instructors, however, have found developing effective online lessons in a very short period very stressful and difficult (Hew et al., 2020). Over the whole of the COVID-19 scenario, there are a broad variety of communication platforms and solutions available to assist in the digitalization of the entire teaching-learning process (Mishra et al., 2020). For many students and faculty members, the COVID-19 pandemic was the trigger that brought them into contact with teaching and learning connections that took place entirely online in a virtual classroom setting for the first time. Academics and students must enter "unfamiliar territory" due to the necessity to quickly adjust to entire e-learning situations 
following the abrupt closure of face-to-face education (Carolan et al., 2020). As a result of the COVID 19 pandemic, entire campus ecosystems for students, professors, and staff were swiftly and drastically changed as public health professionals released rules that strongly opposed any public gatherings and recommended everyone restrict in-person encounters. It is believed that lasting changes will occur and incorporate activities owing to the changes that will take place as a result of the post-pandemic period, often known as the new normal (Telli \& Aydın, 2021).

Almost immediately, schooling went from face-to-face to online because of the arrival of COVID 19. Due to the new mode, lecturers and students alike had no other option than to master the technology as well as all the other surrounding complexities. For many people, this was their first time having this experience. Administrators and instructors of universities faced an abundance of students, new means of delivering educational content, and public anxiety as they had to handle a huge number of responsibilities all at once (Chauan et al., 2020). Likely, each faculty member's level of expertise in the job of the online instructor had a critical influence on how well their courses performed. It was the pandemic required online semester that provided faculty members with their first impressions of teaching in a virtual environment, particularly for those who had no prior experience as online instructors. These faculty members found themselves in a difficult situation since they did not have enough time to organize and prepare a course for online delivery. Selwyn (2007) highlights the fact that instructors often set their practices independently, which means that technological consistency and frequency of use rely exclusively on the desire of the individual teacher, resulting in irregular, inconsistent integration. The experience of these people during the pandemic affected semester is rather unique as online faculty members, because they have been so rapidly entrusted to the job, and because of the seriousness of the pandemic, their desire to teach online courses has become relevant. The mixture of these variables generated a phenomenon that could never have happened before. Some faculty members may be worried about taking on the job of online teacher due to concerns about their teaching style or methodology. Some people's reluctance to teach online, on the other hand, may be motivated by personal reasons.

As a result of the extreme and unusual conditions of the COVID 19 pandemic, a huge and forced online teaching and learning effort was mandated by the authorities. Among other things, the relationship between faculty members' experiences and views of online education, including their choice of instruction in either a traditional or online classroom environment, was tested. Faculty members, who may not have otherwise had the opportunity to take on the position of online teaching, may now share their thoughts and feelings about the online classroom environment with their colleagues. The experiences and interactions encountered by these faculty members may give significant insights into how universities might improve their online teaching and classrooms. The attitudes created by these interactions can be essential to understanding how online learning better meets the needs of all, especially faculty members and students who lack substantial experience online. Faculty members who had never acquired the job of online teaching before the pandemic semester had particularly troubling and inconvenient experiences with their teaching tasks. Their experiences, behaviors, sentiments, and perceptions of the pandemic may help us better understand the dynamics of the online faculty member's role.

The emergency phase has generated truly heroic responses from higher education. But the next phases will be more uncertain. Much will depend upon economic and political circumstances - and on policy decisions. Existing trends are expected to increase, instead of reverse, and underlying flaws and inequities are likely to be highlighted, rather than dramatic shifts. These tendencies have already begun to show signs of development (Hazelkorn, 2021). Rather than evaluating and arguing about the efficiency of the online classroom as an educational format, researchers should look into why the position of the online teacher appears to be more difficult and less enticing to some faculty members. Some professors may believe that online learning is incompatible with their fields of study or teaching techniques. To better match with different fields and personality types, institutions may need to adjust their professional development opportunities linked to online education. There are probably essential components of the conventional classroom that are denied to faculty members that feel their teaching or disciplines are incompatible with online training. An instructor in the formation of an online style of teaching is crucial to adapting these features of a traditional teaching environment. Important areas of concern for higher education institutions are the elements that influenced this process of personal and professional growth for faculty members when for the first time they became involved in online teaching during the pandemic. Due to its unique character, the associated attitudes experienced concurrently by so many faculty members were never examined in any way equivalent to the ones that were generated by the mandatory online shift into instruction in the pandemic semester. In order to help further academics along their journey to the design of the online classroom best suited to their personality, education methods, and disciplines, an analysis of interviews with faculty members without online experience before the pandemic semester might 
be useful.

A new way of proceeding is emerging in higher education. This new form is not a "new normal", but instead a movement towards an educational experience not bounded by limits such as seat time, a rigid calendar, bricks and mortar, and stereotypic notions of learning (Harris \& Santilli, 2021). Although many major colleges and universities provide their faculty members with educational opportunities and resources for their training and awareness to increase their online teaching skills, it is still difficult for individuals to build a sense of personal comfort and natural skills as online instructors. These difficulties may in some circumstances be more due to their characteristics than to their abilities. Due to the short time period since the COVID-19 pandemic began spreading and the pandemic's continuous escalation in the months that followed, higher education society is still unable to complete a comprehensive evaluation of the impact of this phenomenon on faculty. Due to the required transition to online education, all faculty members were compelled to assume the position of online instructor. Their inexperience of expertise lecturing online mixed with the outbreak's very challenging times created a difficult potential for self introspection and growth.

By examining faculty members' perspectives on the future of higher education through their first-time online teaching experiences during the Fall 2021 academic semester, which was impacted by the COVID-19 pandemic, the research will be able to develop a better understanding of their perspectives on the future of higher education. Additionally, this qualitative phenomenological study can contribute to the research on faculty members' accounts of their experiences as first-time online instructors during the pandemic semester and the resulting effects on their perception of and approach to online teaching, both of which are currently under investigation. In light of the COVID 19 pandemic, the move to online learning had an immediate impact on instructors, and an examination of their thoughts and behaviors through in-depth interviews allowed the researchers to record their feelings and experiences. These faculty members' insights may serve to increase faculty members' understanding of important pedagogical concepts crucial to their position as online instructors, and may therefore aid those faculty members who are having difficulty developing their own comfort and competence in online teaching. Despite the fact that faculty members may not have prior online teaching experience, conducting interviews with individuals who have just taken on the job of online instructor as a result of the COVID 19 pandemic may give valuable information about how individuals handle this responsibility. Faculty members will be willing to guide the future of higher education because of how institutions will provide them with the competencies necessary to engage in the teaching strategies of the future. The mentioned faculty members' insights will guide crucial components of how universities go about enhancing their online education frameworks, faculty development programs, and teaching techniques.

The overarching research question is as follows:

- What do faculty members have in mind regarding the future of higher education as a consequence of the COVID-19 pandemic?

The accompanying subsection of questions explores these faculty members' basic experiences and attitudes as a result of the move to online education following the COVID-19 pandemic:

- What was the impact of the COVID-19 pandemic on faculty members who had no prior experience in the role of online instructor before the pandemic?

- What effect did the transition to online education following the COVID - 19 pandemic have on instructional styles of faculty members?

- Following the COVID-19 pandemic, how did institutional support affect the online teaching experience for faculty members?

\section{Method}

For this study, a phenomenological qualitative research design was used. According to Burks and Robbins (2012), the method emphasizes focusing on similarities, variances, and variations in the data. Rather than trying to analyze the research data, the study participants' own accounts of their experiences, feelings, and perceptions were the focus of this study. Phenomenological qualitative research is conducted in the approach outlined by Creswell (2013) and involves identifying phenomena and then interviewing people who have encountered the phenomenon. This material is then compiled to produce a narrative of the entire experience. Because of the anonymous nature of the participants, the unique composite account of the substance of the views of the faculty members questioned does not generalize the experiences of any other online instructors. These interviews provided an insight into what faculty members faced throughout the semester after the pandemic, and how it affected their behavior as online educators. Everyone was asked to discuss their unique online teaching 
experiences with regard to personalities, technology, teaching styles, student involvement, and perceived learning outcomes. The researcher finished the interview by asking the participants to share their thoughts on the impact that these significant events had on their professions as educators. Senior faculty members from several academic fields were selected for this qualitative research study based on criteria of having at least ten years of experience teaching in a typical classroom setting at a public university in Izmir, Turkey, in the fall semester of 2021. The participants in the study group were invited to discuss their experiences, feelings, and impressions when teaching online during the fall of 2021 semester following the COVID 19 pandemic, concluding in semi-structured interviews addressing their duties as online lecturers. This research consists of faculty members' experiences and perspectives following the mandated shift to online education that took place in the fall of 2021. Personal characteristics, as well as the faculty members' views, attitudes, feelings, and individual characteristics, all influenced the results of the study. To discover important information on faculty attitudes about online instruction due of the emergence of the pandemic during the fall of 2021 semester, each interview was evaluated for notable and distinctive replies. Common themes were found in the collective body of interviews after all individual analyses were reviewed and the recurring components were noted. A procedure was created to be used by the research participants after reviewing, modifying, and paraphrasing the answers to interview questions. It included interpretative one-on-one interviews that were taped and analyzed later. The interviews had at least one hour meeting with each faculty member. The participants were told that if they needed more information, they could schedule follow-up meetings. The interview transcripts were transcribed and examined for similar and different subjects and themes in the participants' experiences. The transcripts of the participants were analyzed and summarized using a qualitative hermeneutic phenomenological analysis method, which was guided by narrative analytical techniques and tools (Daiute, 2014).

\section{Results}

\subsection{Main Theme}

The first research question was, "What do faculty members have in mind regarding the future of higher education as a consequence of the COVID-19 pandemic?" and it sought The COVID-19 pandemic has caused faculty members to rethink their perspectives on the future of higher education. For this topic, the theme was derived largely from participants' narratives and interviews with participants, as well as a more in-depth examination of the results. Below was the main theme as "transformation of higher education with hybrid perspective" that emerged from their reflections and expressions of their impressions of the phenomena that they had witnessed and experienced firsthand.

\subsubsection{Transformation of Higher Education with Hybrid Perspective}

There was a greater sense of anticipation as the conversation moved toward the future. They were clearly unprepared to talk about what teaching would be like if the pandemic had completely taken hold. On the other hand, there were some who saw the pandemic as a benefit to higher education. As the globe approaches the time of the COVID-19 pandemic, each faculty member offers their point of view about how their own role, their courses, and their students may be affected. There was a great deal of enthusiasm for all of the faculty members' features as they explained how they feel that conventional on-campus training and online instruction would blend together in order to address the growing global need for education. Faculty members noted the potential for further developments with respect to hybrid instructional approaches. To see how this development may influence their role as instructors, was asked each faculty member to merely contemplate the potential that most higher education lectures may be taught online by the time it happens, and to describe how it might impact them.

Faculty 2 noted that:

"I think we can say the pandemic has made it clear to us that we need to redesign the teaching tools we use but we don't necessarily need to replace our on-campus instruction with an online delivery method because all of us will have the opportunity to be vaccinated."

Faculty 5 said that:

"Online courses have not lessened our desire to perform activities in-person. I hope that these are long-term beneficial improvements, but I also hope that students don't come to the conclusion that, "Well, we tried online and it didn't turn out too badly, so let's just do it all the time."

Faculty 6 reported that:

"I suppose we've returned to where we were before the vaccines, when classes were only offered on-campus. I don't foresee that my teaching methods will have long-term consequences. Right now, in relation to, other students, other schools, and other undergraduate work, I don't know, but I don't believe our 
students have demonstrated an increasing demand for online classes."

Faculty 7 argued that:

"This transition is an amazing chance to learn. Education will never be the same. I fear that switching to online courses will mean students may lose the information and understanding they gained in their classroom instruction, since I really feel there are instructors who have given up. I'm aware that we experienced the same difficulties in my department."

Faculty 10 specified that:

"This proof of concept has already been achieved; online education works without a student being physically present in the classroom. And I believe institutions are now watching the web and saying it may not be the best format, but we do that. Students still enroll and graduate. There will never be any other lectures and conferences other than online, as we do not have to pay for the travel expenses of institutions to participate. I also think we will never return to campus as before, since we will probably have many more online synchronous teachings and I don't believe that's necessarily a negative thing. I think this is true. Let me add, it will provide us with the possibility to work more often globally. I suspect a bigger proportion of our students may either never or hardly ever have found their way onto campus."

Following every interview, it was customary to engage in a debate about the future of how education is given. The main emphasis was on education, although some faculty members noted how they saw changes in campus life, such as social contacts and advising, arising as a result of the pandemic. In other words, much of the attention was on teaching, but a few faculty members also talked about how they saw other areas of campus life, including social relations and advising, changing due to the pandemic.

\subsubsection{Subthemes}

The accompanying subsection of questions explored the faculty members' experiences and attitudes as a result of the move to online education following the COVID-19 pandemic. The following questions; "What was the impact of the COVID-19 pandemic on faculty members who had no prior experience in the role of online instructor before the pandemic?", "What effect did the transition to online education following the COVID-19 pandemic have on the instructional styles of faculty members?" and "Following the COVID-19 pandemic, how did institutional support affect the online teaching experience for faculty members?" were asked of faculty members to explore their basic experiences during online education. The following subthemes emerged from the analysis of the data as "educators on the internet", "sustain and evolve" and "university support".

\subsubsection{Educators on the Internet}

The mandated move to online education pushed every faculty member out of their comfort zone as an instructor, requiring them to reflect and develop their understanding of how to effectively engage their students and deliver their courses.

Faculty 2 claimed that:

"When it comes to online applications, I think the students seem like flat images since there was no roundness to them, and they didn't have any feeling of personal touch. Additionally, when I teach in the classroom, I'm usually quite active and experiential. However, you cannot use the online app like that. Of course, at a distance, it just doesn't have quite the same effect."

Faculty 5 asserted the following:

"Since the delivery mechanism changed, my teaching approach had to alter as well. I try to foster a degree of personal connection with my students, encouraging them to think critically about what we're both learning. I feel that changing to online during the fall semester had a huge impact on our ability to utilize online resources, to say the least. There was even a certain kind of weird gallantry about us all that we'd all go through it together. So, I lowered the expectations I had about what I expected to be able to demand in terms of style. We weren't conducting any meaningful dialogue with them, and neither were they. It was a difficult time for us all, but I did everything I could to assist them and get through it."

Faculty 8 argued that:

"Not only do things have to be prepared long in advance, they also have to be planned down to the minute and managing time is a large part of that. The change to online added additional strain on the faculty member since she was tasked with not only informing the class about what was going to happen that day, but also providing important dates in advance, so that we could all plan in advance." 
Faculty 10 debated the following topics:

"I believe what is difficult is just figuring out how to convey a lesson and make the transitions between different sections of that presentation obvious. When I was in the classroom, I felt like I was the center of attention because of how dramatic my personal presence was, and that was easier to accomplish on Zoom. But even though we're still performers, we have to give lectures, and that's challenging, albeit not quite as much as before. I believe that the hard aspect is in teaching emphasis while conveying the framework of a lecture. I now get more emails from students than I used to, and students may now stick out for longer at the conclusion of class through something we may refer to as "office hours" using a camera. There is a significant difference between online communication and face-to-face conversation."

All the participants asserted that compulsory online education was a challenge for faculty members since it required them to adjust and grow in their understanding of how to best engage and teach their students. As the faculty claims, the mandated shift to online education drove every faculty member away as an instructor out of their comfort zone, demanding that they reflect on and deepen their understanding of how their students may effectively interact and deliver their courses.

\subsubsection{Sustain and Evolve}

As a consequence of the fast and unexpected nature of the COVID-19 pandemic, which prompted a mandated transition to online education, each of these faculty members experienced a survival instinct and began to prepare for long-term survival. Since these faculty members couldn't teach in person, they had to tailor their teaching methods to match the distant setting.

Faculty 4 noted that:

"Even though I will be back at school, I expect there will be some of that, too. My main conclusion is that, yes, I made a conscious decision to keep my teaching style consistent throughout the spring semester when we went online. It took me three or four months to recognize that online is very different and you can change your teaching style to meet the requirements of the assignment."

Faculty 6 reported that:

"On my course, in the end, the students and I dropped out. Because the class as a whole was unprepared and unable to follow through with what we planned to achieve over the semester, we abandoned our initial goals."

Faculty 9 said that.

"As the relationship-building and informal connections I had when I was on-campus were no longer there once we moved to online learning, I was concerned. On top of that, office hours were nonexistent, because I couldn't utilize class time for anything like that. Since it meant I had to come up with new ways to communicate, I had to search for new ideas."

As a result of the sudden and unexpected nature of the pandemic, which resulted in a compulsory shift to online education, each of these faculty members experienced a survival instinct and began to plan for long-term survival as a result of their experiences. Because these faculty members were unable to teach in person, they had to adapt their teaching approaches to accommodate the distance learning environment.

\subsubsection{University Support}

Each faculty member was ready to address the importance of university support in their experience and all appeared to take a very favorable look at their decisions, answers and actions. When it comes to university assistance, the primary point of contention is the timeline for converting all instruction to online delivery and the degree of contact between administrators and executives and academics. On the other hand, faculty members shared how significant they were to the instructional design and support staff members' efforts, particularly for the work they did in developing learning objects and services. Additionally, numerous instructors noted that the instructional technology services personnel had a significant impact on their experiences.

Faculty 1 reported that:

"We had to make numerous unique design considerations due to the fact that we wanted to find a means to have it understood in a distant environment quickly. Everything must go, no ifs, ands, or buts. And all those conversations had to happen very, very quickly. I believe if we had had more time, we would have been better prepared for the move to online, since we would have had a week to do so."

Faculty 2 claimed that: 
"If I had noticed that the university was limiting assistance for professors, I would have assumed that they didn't care as much, therefore their priorities were obviously lower, since I wouldn't have gotten as much aid as I was hoping for. Less rigorous and polished coursework may have resulted as a result, since I wouldn't have felt like it was a significant undertaking because it wasn't encouraged. One of the most essential aspects of the university experience is the supportive community. If I'm not feeling that way, then my motivation is greatly affected."

Faculty 3 noted that:

"We've been discussing for hours about the shutdown, what it means, and how we'll proceed. And all I needed was for someone to simply say, "Hey, we'll do it this way." And that sort of continued into the summer semester, when we were talking about teaching online in the fall semester, but I think people still just wanted someone to tell them what to do, more similarities in the sense of here's what other colleges or departments are doing that seems to be working."

Faculty 8 declared that:

"It was really helpful to have the assistance we received, but it did not change the situation or the facts. Another significant benefit is that students should understand what the expectations are for them as online students, as far as learning the methodologies and best practices. I can say positive enough about our training support. I would have found a solution even if it wasn't for all the assistance. It would have been more difficult at an already stressful time. To be very honest, the institutional support I received was really favorable. I figured they did their best."

Even all faculty members agreed on the significance of university support during their lives and looked with a kind eye at their decisions, responses, and actions. Almost always, decisions to move all teaching online are taken quickly, but there is nearly always a lack of degree of contact between managers and academics. While faculty members have explained how important they are to the design and support of educational personnel, particularly for the founding of educational technologies and services, professors have also commented on how much of an impact they have on the integration of technology and support work of staff. Other academics noticed that the training was impacted by the personnel of training technology services.

\section{Discussion}

With the COVID-19 pandemic, people's daily lives have been irrevocably affected regardless of whether or not there is a public health catastrophe. Vaccinations and further efforts to restore everyday living will create a new reality rather than a restoration to life as it was before. Most of the world population, driven by the fast spread of the outbreak and lengthy transmission mitigation procedures, found new ways to conduct their daily tasks, learn, and connect with others. These lessons cannot be forgotten or ignored, the changes are not forgotten, or development cannot be reversed. The sustainability of higher education institutions around the globe following COVID-19 will significantly depend on technological integration to develop a dynamic campus environment which relies on a seamless blend of interaction between people and distant places (Drayton \& Waltman 2020). Three variables that will always be present in every classroom: the educator, the subjects and the students will dynamically and continually influence the environment of this hybridized ecosystem. When considering the sensitive atmosphere of any mixed or online classroom, one cannot underestimate the combined influence these three elements possess.

A perspective is the single most important component in determining the climate of a hybrid or online classroom, but students, in contrast, have a considerably greater influence. Although the institution has a significant amount of power and contains huge quantities of information and expertise, it is the student body that profoundly influences each instructor's attitude. The influence that students' creativity, excitement, hard work, professionalism, and humanity have on the instructor is greater than all other factors combined. No matter how reluctant or resistant educators may be, when students take the initiative and seek new solutions and exciting opportunities in the blended or online classroom, their professors are typically just as eager to participate. When it comes to how the classroom is managed, the instructor acts like a legislature. According to Akyol \& Arslan (2016), there is a lack of research to suggest that the use of digital technology is more prevalent for classroom management activities, but there is significant research that demonstrates its use for didactic activities. In the same way, students are similar to members and therefore have power over the university's culture. Students are very flexible since they have complete flexibility in the blended or online classroom to decide how deeply they will participate, and so they are the most powerful force in building a rich classroom experience because of their ability to affect educators. 
The responsibility of fostering the desire, professionalism, and involvement of the collective student body is sometimes too much for professors to carry. In a hybrid or online classroom, students have a much greater impact on their own education than in a typical on-campus class (Xie et al., 2020). Students that put less time and care into this environment will see a decline in their well-being and education. While the institution does lay out basic principles that everyone must maintain as a part of the campus community, it also retains more authority in regulating what students can and cannot do because it is the source of the community's standards of behavior. While many of the same concepts are employed both in the traditional classroom and in the online learning environment, the online setting is in need of a few particular rules that should be adhered to by both the instructor and the students while interacting in a remote capacity. The development of readily available student-focused training and support resources is especially important for students, whose behaviors directly and significantly impact the quality of their online learning experience.

When it comes to faculty members and online teaching, it may be a stressful process for them because the online classroom might seem very different from the regular classroom. Faculty should talk to their colleagues and students before moving into the online classroom, since both can offer useful advice. Information in these sources may appear small, but minor changes often have a significant influence on the enthusiasm and engagement level of an online class. A good example of this is new technology that can help foster a sense of collaboration. Another possibility is that the investment of class time for online students has diminished the perceived value of an exercise. Each member of the faculty needs to understand and embrace the idea that online education is flexible because of the presence of technology. Instructional methods designed to stay in step with technology advances and trends and that are actively encouraged by instructors will likely lead to higher levels of engagement. While learning in the time of COVID 19 has been challenging for students and prospective teachers alike, this moment of disruption has created the opportunity for rethinking and reinventing preparation, as well as schooling itself (Darling-Hammond \& Hyler, 2020). The impact of COVID-19 on education is undeniable. Looking back, we may come to realize the positive impacts the crisis has had on instruction, including gathering resources that allow teachers to extend student content knowledge, providing new ways for students to demonstrate their understanding, and offering exciting opportunities for peers to collaborate (Mason-Williams et al., 2020). Higher education, a sector that is not known for rapid change, will have to adapt quickly. In order to fulfill their missions, higher education institutions will have to be creative about how to engage students, conduct research and serve communities. Overall, institutions of higher education will have to demonstrate their role as anchor institutions in their communities more than ever in order to help communities rebuild in the wake of the pandemic. The various ways in which colleges and universities have been engaging with their communities in recent months is only the beginning. In all aspects of life - education, health, economic development and others disparities have deepened. Institutions of higher education's future worth to society will be determined by their capacity to assist the most vulnerable populations through democratic community partnerships (Maurasse, 2021).

Putting the transformation created in higher education by COVID-19 in the framework of a wider discourse on implementation in higher education, according to the findings of this study, aids in comprehending the nature of the transformation and its symptoms. This analysis also assists us in identifying who is responding to the new normal and how they are responding; it identifies limitations, and even mistakes, in the efforts to address the current situation; and it allows us to identify or confirm recommendations for action.

Based on these findings, higher education administrators and faculty may further improve their ways of delivering high-quality online programs and courses while also refining their approaches to remote instruction in crises situations. There should be additional research to address the interaction between the teacher, the discipline, and the students in the online classroom. Furthermore, in order to properly assess students' sensitivity, emotional support, and digital citizenship, it is necessary to conduct research pertaining to these three topics during the pandemic.

\section{References}

Akyol, B., \& Arslan, H. (2014). The evaluation of higher education problems in Turkey. European Scientific Journal, 10(7), 71-84. https://doi.org/10.19044/esj.2014.v10n7p\%25p

Arslan, H., \& Ulutaş, M. (2017). Relationship between Informatics Leadership, Learning Organization. In D. Icbay, (Ed.), University Culture in Higher Education in Rsearch on Education Arslan (pp. 321-337). E-BWN - Bialystok.

Carolan, C., Davies, C. L., Crookes, P., McGhee, S., \& Rox-Burgh, M. (2020). COVID 19: disruptive impacts and transformative opportunities in undergraduate nurse education. Nurse Educ. Pract., 46, 102807. 
https://doi.org/10.1016/j.nepr.2020.102807

Chauhan, S., Gupta, P., Palvia, S., \& Jaiswal, M. (2020). Information technology transforming higher education: A meta-analytic review. Journal of Information Technology Case and Application Research, 23(1), 3-35. https://doi.org/10.1080/15228053.2020.1846480

Darling-Hammond, L., \& Hyler, M., E. (2020) Preparing educators for the time of COVID and beyond. European Journal of Teacher Education, 43(4), 457-465. https://doi.org/10.1080/02619768.2020.1816961

Drayton, E., \& Waltman, B. (2020). Will universities need a bailout to survive the COVID-19 crisis?. London: Institute of Fiscal Studies.

Harris, J. T., \& Santilli, N. R. (2021). Higher education should embrace this liminal moment because there will be no "new normal". In S. Bergan, T. Gallagher, I. Harkavy, R. Munck \& H.van't Land (Eds.), Council of Europe Higher Education Series (pp. 129-136).

Hazelkorn, E. (2021). Some challenges facing higher education in Europe in view of the Covid-19 pandemic. In S. Bergan, T. Gallagher, I. Harkavy, R. Munck \& H.van't Land (Eds.), Council of Europe Higher Education Series (pp. 53-66).

Hew, K. F., Jia, C, Gonda, D. E., \& Bai, S. (2020). Transitioning to the "new normal" of learning in unpredictable times: pedagogical practices and learning performance in fully online flipped classrooms. Int J Educ Technol High Educ, 17, 57. https://doi.org/10.1186/s41239-020-00234-x

Jensen, T. (2019). Higher Education in the Digital Era: The Current State of Transformation around the World. International Association of Universities (IAU).

Johnson, L., Adams, B. S., Cummins, M., Estrada, V., Freeman, A., \& Hall, C. (2016). NMC Horizon Report: 2016.Higher Education Edition. Austin, Texas: The New Media Consortium.

Mason-Williams, L., Rosenberg, M., Kimmel, L., \& Sindelar, P. (2020). Addressing Shortages of Educators in an Uncertain COVID-19 Landscape: Viewing Teacher Candidates as Assets. Gainesville, FL: CEEDAR Center.

Maurasse, D. (2021). Challenges to US higher education in performing local missions during and after the Covid-19 pandemic. In S. Bergan, T. Gallagher, I. Harkavy, R. Munck \& H. van't Land (Eds.), Council of Europe Higher Education Series (pp. 66-77). Higher education's response to the Covid-19 pandemic.

Mishra, L., Gupta, T., \& Shree, A. (2020). Online teaching-learning in higher education during lockdown period of COVID-19 pandemic. Int. J. Educ. Res., 1, 100012. https://doi.org/10.1016/j.ijedro.2020.100012

Selwyn, N. (2007). The use of computer technology in university teaching and learning: To critical perspective. Journal of Computer Assisted Learning, 23, 83-94. https://doi.org/10.1111/j.1365-2729.2006.00204.x

Telli, S. G., \& Aydın, S. (2021). Covid-19 sonrası dönemde işletme bölümlerinin Dijital Çağ'a yönelik hazır bulunuşluğu: Türkiye örneği. Yükseköğretim Dergisi, 11(1), 123-138. https://doi.org/10.2399/yod.20.009000

Xie, X., Siau, K., \& Nah, F. F.-H. (2020). COVID-19 pandemic - Online education in the new normal and the next normal. Journal of Information Technology Case and Application Research, 22(3), 175-187. https://doi.org/10.1080/15228053.2020.1824884

\section{Copyrights}

Copyright for this article is retained by the author(s), with first publication rights granted to the journal.

This is an open-access article distributed under the terms and conditions of the Creative Commons Attribution license (http://creativecommons.org/licenses/by/4.0/). 